\title{
Análisis histórico - constructivo de la iglesia de Santo Domingo de Guzmán (Pajarejos, Segovia) por medio del análisis estratigráfico constructivo
}

\author{
María del Cisne Aguirre U. ${ }^{1}$, Álvaro J. Álvarez G. ${ }^{1}$ \\ ${ }^{1}$ Investigadores independientes. \\ Autor para correspondencia: cisne2222@hotmail.com \\ Fecha de recepción: 26 de enero de 2015 - Fecha de aceptación: 15 de mayo de 2015
}

\begin{abstract}
RESUMEN
El artículo ilustra el potencial del análisis estratigráfico, un método arqueológico para leer la información contenida en los paramentos, para la obtención datos y la documentación del patrimonio arquitectónico. Las vicisitudes del método configuran un modelo especializado de carácter constructivo dentro del proceso de documentación patrimonial, más allá del conocimiento histórico y el análisis tipológico. Tomando como fuente primaria el propio edificio, se aplica un procedimiento lógico y contextualizado de los elementos legibles y tangibles, deduciendo de manera técnica el conjunto de campañas constructivas que lo han conformado hasta su estado actual. Su inclusión previa a cualquier actuación en un bien patrimonial, contribuye a mejorar el entendimiento y la toma de postura ante cualquier intervención en el bien arquitectónico.

El estudio estratigráfico detallado de la iglesia románica de Santo Domingo de Guzmán (Castilla y León, España) ha demostrado claramente las virtudes del método, ante la carencia de estudios previos y la limitada disponibilidad de referencias históricas. El estudio, inédito a nivel arquitectónico, delimitó trece fases constructivas, específicas y complementarias comprendidas entre el siglo XII y la actualidad.
\end{abstract}

Palabras clave: Arqueología aplicada, método estratigráfico, lectura de paramentos, Pajarejos, Románico Segoviano, investigación histórica.

\begin{abstract}
The article illustrates the potential of stratigraphic analysis, an archaeological method reading the information contained on surfaces, enabling the acquisition of knowledge and the documentation of architectural heritage. The vicissitudes of the method permit to reconstruct the architectural stratification of heritage buildings, yielding more in-depth knowledge than what can be derived through historical and typological analysis. The approach involves the application of a logic and contextualized stratigraphic survey of the legible and tangible elements of the building, the primary source, enabling the reestablishment of the chronology of technical and constructive interventions that have led to the current appearance of the building. Consideration of this knowledge, prior to any new interference, will automatically result in a more rational and justified intervention in heritage assets.

The detailed stratigraphic study of the Romanesque church of Santo Domingo de Guzmán (Castilla and León, Spain) has clearly demonstrated the virtues of the method, and this in the absence of previous studies and the limited availability of historical references. The study revealed the succession of thirteen specific and complementary phases of constructive campaigns between the twelfth century and today, previously architectonically not documented.
\end{abstract}

Keywords: Applied archeology, stratigraphic method, wall reading, Pajarejos, Romanesque Segoviano, historic research. 


\section{INTRODUCCIÓN}

La reciente relevancia del análisis estratigráfico aplicado a la arquitectura ha puesto en entredicho los procedimientos de caracterización de dicho patrimonio. En este sentido, el ejercicio teórico-práctico de la asignatura de Arqueología de la Arquitectura, en la convocatoria 2013-2014 del Máster Universitario en Conservación y Restauración del Patrimonio Arquitectónico de la Escuela Técnica Superior de Arquitectura de la Universidad Politécnica de Madrid, se fundamentó en la lectura del trasdós de los paramentos de la Iglesia de Santo Domingo de Guzmán en el municipio segoviano de Pajarejos (Castilla y León, España). Este análisis pormenorizado permitió identificar cada una de las fases constructivas del templo románico, que apenas cuenta con referencias documentales y analíticas. La única descripción se recoge en la Enciclopedia del Románico impulsada por la Fundación Santa María la Real ${ }^{1}$. Ante este vacío documental, resulta evidente emprender esta ardua tarea de identificación, levantamiento y análisis arquitectónico, no sólo en Pajarejos, sino en todo el territorio circundante, con el fin de identificar y analizar los rasgos tipológicos de identidad a nivel local, que animen a evitar la continua despoblación del medio, aún rural. La investigación asume así una doble finalidad: apoyar el empleo del método, analizando aquellos pormenores que han de ser subsanados al caracterizar estratigráficamente el objeto de estudio, así como paliar el desinterés social y la escasez de estudios en la zona. Ante estas pretensiones y pese a su carácter académico ${ }^{2}$, la investigación se concibió en todo momento con máxima objetividad tanto en procedimientos como en resultados.

El análisis estratigráfico arquitectónico cuenta con numerosos partidarios, quienes aportan nuevas problemáticas y discusiones a su ejecución, implementación, e incluso a la propia terminología. Siguiendo la propuesta de Mileto \& Vegas (2003), bajo el auspicio de Luis Caballero Zoreda, se propone usar el término análisis estratigráfico constructivo ya que se trata de un análisis, y no solamente de una lectura (Caballero Zoreda, 1995: 37-38). Este conflicto proviene de la propia arqueología desde la contribución de Harris (1991) a través de su libro, Principios de estratigrafía arqueológica, aunque años antes el método ya viera la luz. Edward Harris establece los principios necesarios para la identificación de cada estrato en excavaciones de índole arqueológica. El desarrollo posterior propuesto por los profesores Parenti y Brogiolo en la Cátedra de Arqueología Medieval de la Universidad de Siena, evidenció la necesidad de mejorarlo para su correcta aplicación en arquitectura, al precisar de un conocimiento específico de los procesos constructivos ligados al desarrollo de la obra, al contexto cultural, y a las técnicas constructivas locales (Doglioni, 1997). El desarrollo de esta metodología, proviene del campo pluridisciplinar, exigiendo a los arqueólogos el conocimiento de las técnicas constructivas de los edificios, y a los arquitectos el reconocimiento del carácter estratificado de la edificación (González-Moro \& Caballero Zoreda, 1995).

De cara a su faceta práctica, el análisis estratigráfico entra en conflicto con otros campos científicos en aras de fomentar el conocimiento del bien patrimonial. La problemática reside en la hegemonía ostentada por ciertas áreas de conocimiento de corte teórico frente a procedimientos prácticos (Latorre \& Caballero, 1995). Brogiolo (1995) determina vías de actuación recíprocas en el conocimiento del bien edificado, resultado de la interacción de la historia de la arquitectura, los instrumentos científico-técnicos y los aspectos teóricos y prácticos de la restauración arquitectónica. La propuesta confronta teoría y práctica de manera sinérgica al entender el bien edificado como elemento estratificado producto de la historia. Ligado al planteamiento práctico, Mileto \& Vegas (2004) identifican el método para la formulación de hipótesis de las fases y periodos constructivos del edificio o las fábricas analizadas. Al mismo, y de manera exhaustiva, los materiales y técnicas constructivas en su relación estratigráfica y dentro de una cronología relativa, que posibilitan la aplicación del conocimiento de la historia de la cultura material. Los resultados orientan al establecimiento de comparaciones dentro de una holística subyacente al elemento individual, capaz de configurar la génesis constructiva y tipológica de un territorio. En este campo el desarrollo de

\footnotetext{
1 Fundación Cultural, ubicada en el Monasterio de Santa María La Real de Aguilar de Campoo (Palencia) principal impulsor del Patrimonio Cultural en Castilla y León.

2 Paralelamente, se efectuaron trabajos de igual magnitud y alcance, sobre otros seis edificios de similares características a escasos kilómetros del objeto de estudio, los cuales históricamente formaban parte de las Comunidades de Villa y Tierra de Sepúlveda y Maderuelo.
} 
cronotipologías, como las realizada para el estudio de los recintos del Alcázar de Sevilla (Vargas Lorenzo, 2013: 12-16), o el Castillo de Sorriovoli (Fiorini, 2011: 228), son ejemplos de interés, así como el análisis metrológico, fotogramétrico, los estudios de procesos patológicos y deterioro (Rolón \& Rotondaro, 2010: 220) y los análisis de laboratorio (Barluenga et al., 2014: 39), que contribuyen a generar conocimiento trascendental, desde la identificación de particularidades del patrimonio edificado.

Aun frente a la diversidad de opiniones, no cabe duda que el análisis estratigráfico concibe el edificio como resultado de un proceso continuo en el tiempo, donde cualquier reforma originada por la modificación de uno de estos valores incidirá inmediatamente en los restantes. Las partes que conforman todo edificio histórico forman un sistema complejo que no responde de modo lineal a las transformaciones que sobre él se introducen. Ligado a este planteamiento, el análisis estratigráfico de paramentos, permite un estudio minucioso desde una visión objetiva y sistemática, en base al reconocimiento del edificio como estructura orgánica y en permanente cambio (Lecanda, 2003: 161).

En los últimos veinte años, diferentes investigadores se han ocupado de sistematizar el método, entre ellos Brogiolo, Parenti, como promotores, pero también Francovich, Mannoni, Doglioni, Caballero, etc. (Parenti, 1988; Brogiolo, 1988a \& 1988b). Muchos reconocen la imposibilidad de lograr una metodología unitaria a causa de su complejidad. Sin embargo, ésta se asume como virtud, frente a la rigidez de otros tipos de estudios, al adaptarse a diferentes situaciones, bajo los principios y el rigor de las fases de estudio (Mileto \& Vegas, 2004). En cada aportación subyace principios comunes y directivas metodológicas, pudiéndose identificar tres fases: la observación de datos, la documentación e interpretación, -con la creación de distintas secuencias estratigráficas e hipótesis interpretativas-. Estas tres fases se intentan mantener rigurosamente separadas y consecutivas para garantizar la mayor objetividad posible en la recogida de información. Con este conjunto de procedimientos, se diferencian, ordenan y datan las fases por las que han pasado los edificios hasta llegar a su estadio actual, analizando todos los elementos que los componen y que se les fueron añadiendo históricamente. Se trata, la lectura estratigráfica por tanto, de un método con finalidad histórica, alta influencia constructiva y claras aplicaciones prácticas. Entre la diversidad de propuestas metodológicas, el planteamiento de Caballero Zoreda sobresale (Caballero Zoreda, 1995).

Otra línea de argumentación en la práctica se basa en los criterios de intervención según resultados obtenidos (Mileto \& Vegas, 2003). Mileto \& Vegas, con base en las aportaciones de González-Moro \& Caballero Zoreda (1995), exponen las principales líneas, cuestionando beneficios y perjuicios, así como su trascendencia sobre futuras actuaciones. El conocimiento y documentación de la unidad contextual del edificio será imprescindible para el conocimiento histórico y constructivo. Se busca "leer el documento construido" para reconocer todos sus valores y, a partir de este, tener la posibilidad de acometer su restauración, desde la riqueza de relaciones que se producen entre los materiales coexistentes. Así, el análisis estratigráfico ha ocupado un punto clave en la restauración monumental, ofreciendo una respuesta analítica y concreta, ante la hegemonía de la identificación del patrimonio según términos formales, estéticos o literarios (Caballero Zoreda, 1995; Azkarate, 2010).

Con el fin de generar argumentos precisos derivados de la discusión, el análisis estratigráfico se ratifica como una herramienta por excelencia para usar a la edificación como principal objeto de estudio, relegando a un segundo plano la documentación histórica. Consecuentemente, permite obtener las etapas constructivas del objeto arquitectónico, diferenciando los elementos que pertenecen a cada una de ellas, sus relaciones y las actividades constructivas y destructivas que lo provocaron. Permite entender el proceso diacrónico de construcción, crecimiento y transformación del edificio, a partir de un riguroso análisis, descripción y documentación de los elementos constructivos. Las posibilidades objetivas del método amplía el conocimiento sistemático y ordenado del patrimonio edificado, a la vez de manifestar su controversia con las teorías puramente estilísticas que han predominado.

Desde la actuación sobre el bien patrimonio, el método otorga criterios de actuación en función de las intenciones del arquitecto proyectista desde la reintegración o recuperación de la imagen tipológica, la revalorización del espacio arquitectónico y urbano, en algunos casos, la conservación de 
los datos materiales como fuente primaria para investigaciones futuras, el diseño de planes de actuación de índole urbanística y patrimonial y la conservación preventiva, sin olvidar la relevancia sistemática del objeto. Por último, este estudio del patrimonio arquitectónico y su entendimiento como un producto social, conlleva su conservación para la comprensión del pasado. Para la base académica, donde se forja el presente estudio será, el objetivo fundamental, el determinar y caracterizar cada una de las campañas constructivas que han dado pie al conjunto arquitectónico actual, así como demostrar verazmente las hipótesis establecidas a priori sobre las relaciones deducidas desde la observación, y sin un conocimiento documental previo.

\section{METODOLOGÍA, HERRAMIENTAS Y PROCESO}

La Iglesia de Santo Domingo de Guzmán se presenta como un conjunto heterodoxo constituido por elementos discrepantes que no responden a una idea unitaria. Su evolución, tanto constructiva como formal, se revela a través de huellas, que en base a la rigurosidad científica y técnica, y la reivindicación de todos los momentos constructivos, independientemente de su antigüedad o aparente importancia, otorga la oportunidad de generar un planteamiento ontológico y holístico (Tabales Rodríguez, 2002). En este contexto, se recurre al contexto del método estratigráfico para el conocimiento del edificio, empleándolo como herramienta de análisis. De las tres fases en las que se puede englobar el procedimiento, resulta preciso especificar las subfases (Caballero Zoreda, 1995) necesarias para su aplicación:

a) Documentación gráfica del edificio, con especial interés en los paramentos exteriores: ante la falta de documentación previa, para el caso de estudio se incluye el levantamiento planimétrico base $^{3}$ y reconocimientos in situ, acompañado del registro fotográfico abarcando diversas escalas -emplazamiento urbano, caracterización de alzados, detalles constructivos, etc.

b) Diferenciación, numeración y descripción de elementos: se identifica cada Unidad Estratigráfica Muraria -UEM- y determinan las relaciones de proximidad material y constructiva con base en los Principios de la Estratigrafía (Caballero Zoreda, 1995: 39). La observación, identificación y rotulación ${ }^{4}$, de la totalidad (Sánchez Zufiaurre, 2004) de estas discontinuidades constructivas visibles en los paramentos, se realizó bajo un mecanismo propio de codificación: primer dígito indicativo de la orientación relativa de cada UEM respecto a cada alzado, seguido de un número secuencial, no siempre vinculado al orden de visualización. ${ }^{5}$

Aunando estos dos estadios iniciales, se elabora la documentación gráfica: se conformaron ortofotos usando el software Photomodeler Scanner, alzados fotogramétricos con Adobe Photoshop y dibujos técnicos -plantas y alzados-, con Autocad Autodesk. ${ }^{6}$ Una vez obtenido un levantamiento apto, se procede a la delimitación de las UEM sobre los alzados, al tiempo que se comprueban las anotaciones de la toma de datos in situ. En ocasiones es, y fue necesario contrastar las características de ciertas UEM, permitiendo mantener la veracidad y objetividad. Este proceso analítico considera tanto el reconocimiento de nuevas UEM, como la disgregación otras, en función de una lectura holística. Durante la descripción, se generaron fichas analíticas de cada una de las unidades históricas (interfaces y estructuras). Cada una recoge los siguientes campos tanto en gráfico como en texto: identificación, descripción, acciones que crearon la UEM y las relaciones con las demás, en cuadro y

\footnotetext{
3 Se emplearon herramientas técnicas como distanciómetro láser Bosch X25, cinta métrica, flexómetro rígido y jalón. Posteriormente se complementará con el procesamiento gráfico y técnico usando herramientas informáticas.

4 El investigador Azkarate (2010: 59) recomienda la georreferenciación de las UEM.

5 Atendiendo a dicho concepto, la codificación se consigue ajustar a las condiciones de las unidades, aspecto que bajo la opinión de Caballero Zoreda, predicho por Parenti (1988), sería potencialmente aleatorio a diferencia de la arqueología de excavación y, por tanto, con repercusión directa en los resultados finales, ya que resulta en definitiva imposible el hacer coincidir en una primera aproximación el "orden" de numeración con el histórico de deposición.

6 Técnicas como la fotogrametría para la generación de modelos tridimensionales, constituye una herramienta de interés para ejecutar este tipo de tareas, así como para incrementar el nivel técnico de documentación.
} 
diagrama. Aunque investigadores experimentados lo recomiendan, como Caballero Zoreda (1995), no se ha optado por el desarrollo del primero, sin que esto signifique menor precisión y minuciosidad, condición que demanda la complejidad del objeto en estudio. Este proceso permitió comparar, relacionar y precisar aquellos aspectos de carácter problemático, para avanzar hacia la siguiente subfase:

c) Lectura de relaciones temporales y construcción de diagramas: gracias a la elaboración de tantas fichas como unidades detectadas, es posible establecer una primera aproximación, apoyados en los criterios de homogeneidad, individualidad y temporalidad. Al respecto existen varias opiniones, algunas para el análisis de las relaciones estratigráficas/ constructivas desde la convergencia de tres lecturas: la situación espacial que lleva emparejada la acción constructiva, que a su vez deriva en una secuencia temporal -de coetaneidad o de antero/postereoridad para vislumbrar un acercamiento primario a lo que sería la evolución histórica- constructiva del edificio (Caballero Zoreda, 2004; Doglioni, 1988: 231, citando a Manacorda, 1989:12). Este proceso por tanto ordena los elementos cronológicamente según sus relaciones de diacronía, en columnas, y de sincronía en líneas horizontales. La descripción pormenorizada y ordenada por zonas ${ }^{7}$ permite generar una lectura identificativa de gran rigor, permitiendo corroborar cada relación.

d) Reducción, periodización y correlación: con base en the Harris Matrix, se procesa la información obtenida mediante parámetros de simplificación, correlación y periodización, eliminado las relaciones redundantes, suprimiendo las intermedias y reduciendo a una, las relaciones complejas. Este primer planteamiento no busca una definición de fases temporales vinculadas a la periodización histórica clásica, sino atiende a momentos constructivos, es decir, a cada fase constructiva acometida (Harris, 1991: 159). La configuración del diagrama se realiza en dos fases: la primera según la relación puramente física de los estratos, indicando su condición temporal y apoyados nuevamente en los Principios Estratigráficos de Harris (Caballero Zoreda, 1995: 39); y la segunda engloba la clasificación atendiendo a priori a aquellas fases que podrían constituirse una misma ${ }^{8}$. A criterio de Mileto \& Vegas (2003) es casi imposible o por lo menos notablemente arriesgado intentar un diagrama del edificio entero, en lo que coincidimos y optamos por la definición de cuatro, uno por cada paramento analizado.

e) Documentación histórica: establecida una cronología relativa, se procede a la identificación de la cronología absoluta de índole histórica. Las fuentes documentales permiten dotar de veracidad al procedimiento, o poner en tela de juicio el conflicto de la aportación literaria o lo construido. En el caso de la Iglesia de Santo Domingo de Guzmán, debido a la escasa documentación identificada ${ }^{9}$, la lectura estratigráfica ha sido la principal fuente de información, permitiendo entender al edificio como documento histórico y como objeto arquitectónico ${ }^{10}$, y a la vez abrir nuevos campos de estudio sobre el edificio y el territorio al que se pertenece.

f) Síntesis: como fin último, se procede a la configuración de la hipótesis evolutiva apoyada en la documentación generada. Por consiguiente, el análisis de la documentación histórica y el conflicto con los datos obtenidos conlleva datar el proceso constructivo. El punto de máxima

7 La aplicación de bloques clasificatorios también puede ser aplicada, Brogiolo (1995) los define así: CA: El complejo arquitectónico; CF: El cuerpo de fábrica; PG: la fachada o los alzados externos; PP: el desarrollo de los alzados particulares internos, UF: la unidad funcional; SO: la superficie horizontal; EA: elemento arquitectónico (Tabales Rodríguez, 2002).

8 Haciendo un símil en el ámbito de la arqueología de excavación, el procedimiento equivale al seguido para el análisis de plantas compuestas (Harris, 1991).

9 Se ha tenido acceso al Libro de Fábricas de la parroquia que documenta diferentes intervenciones en los siglos XVI y XVII, y al archivo de la Diócesis de Segovia donde se describe una visita realizada al edificio en 1794. La documentación fue facilitada por Gonzalo López-Muñiz, experimentado documentalista español.

${ }^{10}$ Por lo que respecta al monumento como documento, el arquitecto debe promover el análisis previo mediante un estudio arqueológico. Sin embargo éste no tendrá necesariamente una vinculación directa con el proyecto, salvo en el caso en el que se trata de un edificio en ruina y desuso. Considerando el monumento como objeto arquitectónico, debe asumirse la necesidad de actuar de formar que el arquitecto aporte lo mejor que tenga al edificio como una fase más de las que éste manifiesta, de igual modo que en su momento cada arquitecto incorporó según su época los gustos estilísticos en boga (Tabales Rodríguez, 2002). 
representación es la configuración de plantas y alzados delineando cada fase, así como la construcción definitiva de the Harris Matrix.

g) Archivo de datos/publicación: desde el primer momento, las vicisitudes del análisis estratigráfico facilitan el conocimiento detallado del bien edificado con el fin de promover y agilitar nuevas lecturas, así como entender la evolución de la población. En el presente caso, el estudio representa un esfuerzo que aboga, y no en vano a emprender futuras empresas.

\section{RESULTADOS}

Fruto de la aplicación del análisis se han precisado las campañas constructivas de la iglesia de Santo Domingo de Guzmán, contrastando y ampliando su caracterización mediante otros estudios sincrónicos. La investigación se orienta en base al rigor técnico y científico, la reivindicación de todas las etapas arquitectónicas y la oportunidad de generar un planteamiento holístico. Como resultado se narra e ilustra la evolución del templo utilizando el conjunto de documentación generada ${ }^{11}$, y la percepción inicial del edificio que con orientación Este-Oeste, caracterizado por una nave central de planta rectangular rematada por la cabecera absidial con decoración puntual. Sobre el muro Este se alza la espadaña, mientras en los flancos Norte y Sur es visible la adición de volúmenes, dando lugar al almacén y atrio, respectivamente, definiendo la imagen actual del edificio. A modo de coronación, la cubierta de teja al estilo segoviano se asienta sobre una sutil cornisa constituida por una doble hilada de piezas cerámicas, a excepción del pórtico.

Superado este reconocimiento del edificio, se atiende al proceso histórico-evolutivo resultado de la lectura estratigráfica y la documentación histórica. Su origen constructivo se inicia en la cabecera absidial, posiblemente del siglo XII-XIII, junto con el desarrollo longitudinal de parte de la nave hasta el siglo XIV. La configuración románica de elementos arquitectónicos como los vanos del ábside o las muestras escultóricas del acceso principal al $\mathrm{Sur}^{12}$, independiente del pórtico, incita a pensar en una iglesia primigenia de nave única ${ }^{13}$ y escaso desarrollo longitudinal ${ }^{14}$, más cuando el revestimiento de los paramentos interiores hace imposible la identificación de cualquier signo evolutivo, a diferencia de los exteriores (ver Imagen 1: Detalle de vano).

Muestra de ello es la alteración de sillares en el zócalo próximo al acceso del atrio, donde un corte da paso a dos sillares de gran formato, junto con un tercero recortado en forma de L. La ruptura también afecta a la línea de imposta muy pronunciada en el trasdós del ábside. Este hecho corrobora las ampliaciones o remodelaciones posibles de una fase inicial del templo primitivo. Por otra parte, el revestimiento exterior dota de cierta homogeneidad a la composición del ábside, dejando al descubierto las relaciones internas del conjunto, como resultado de las lesiones patológicas. La identificación puntual de sillares en zócalo, vanos y una parte ínfima del muro de mampostería que

\footnotetext{
${ }^{11}$ La producción gráfica sobre la cual se determinó la secuencia histórico-constructiva del edificio, enmarca 4 mapas estratigráficos, 4 líneas cronológicas, 172 fichas de UEM, distribuidas en 36, 52, 55 y 29, de los paramentos Norte, Sur, Este y Oeste, respectivamente.

$12 \mathrm{El}$ acceso a la nave se efectúa por el Este, a la altura del atrio, hasta la puerta principal. La composición arquitectónica de la entrada destaca frente a la sobriedad y blancura de los paramentos colindantes. Se resuelve siguiendo los cánones decorativos del románico: puerta abocinada de escaso desarrollo con una sucesión de arquivoltas, quedando la última suspendida. Una pila bautismal contigua a la puerta, de corte semiesférico y con escuetos símbolos religiosos completa el acceso.

13 Según De Hoz Onrubia, una de las características de los templos románicos de la Extremadura Castellana es la de planta de una sola nave, con cubierta a dos aguas sobre estructura de madera, cabecera absidal a levante y un atrio porticado en su cara sur, a veces con vuelta al lado de poniente.

14 Edificios con parecidas características morfotipológicas en términos generales son, la iglesia de Nuestra Señora de la Asunción de Duratón, el templo dedicado a San Pedro en Perorrubio, la iglesia de la Virgen de la Peña en Sepúlveda y la ermita de Santa María de Termes en Ayllón, entre las provincias de Segovia y Soria, etc. (De Hoz Onrubia et al., 2006).
} 
configura el paramento, hacen posible establecer la relación temporal con cierta exactitud ${ }^{15}$. Sobre el revestimiento se han aplicado reparaciones a manera de parcheado, especialmente de mortero de cemento ${ }^{16}$ con diferentes tonalidades, y de posible origen moderno.

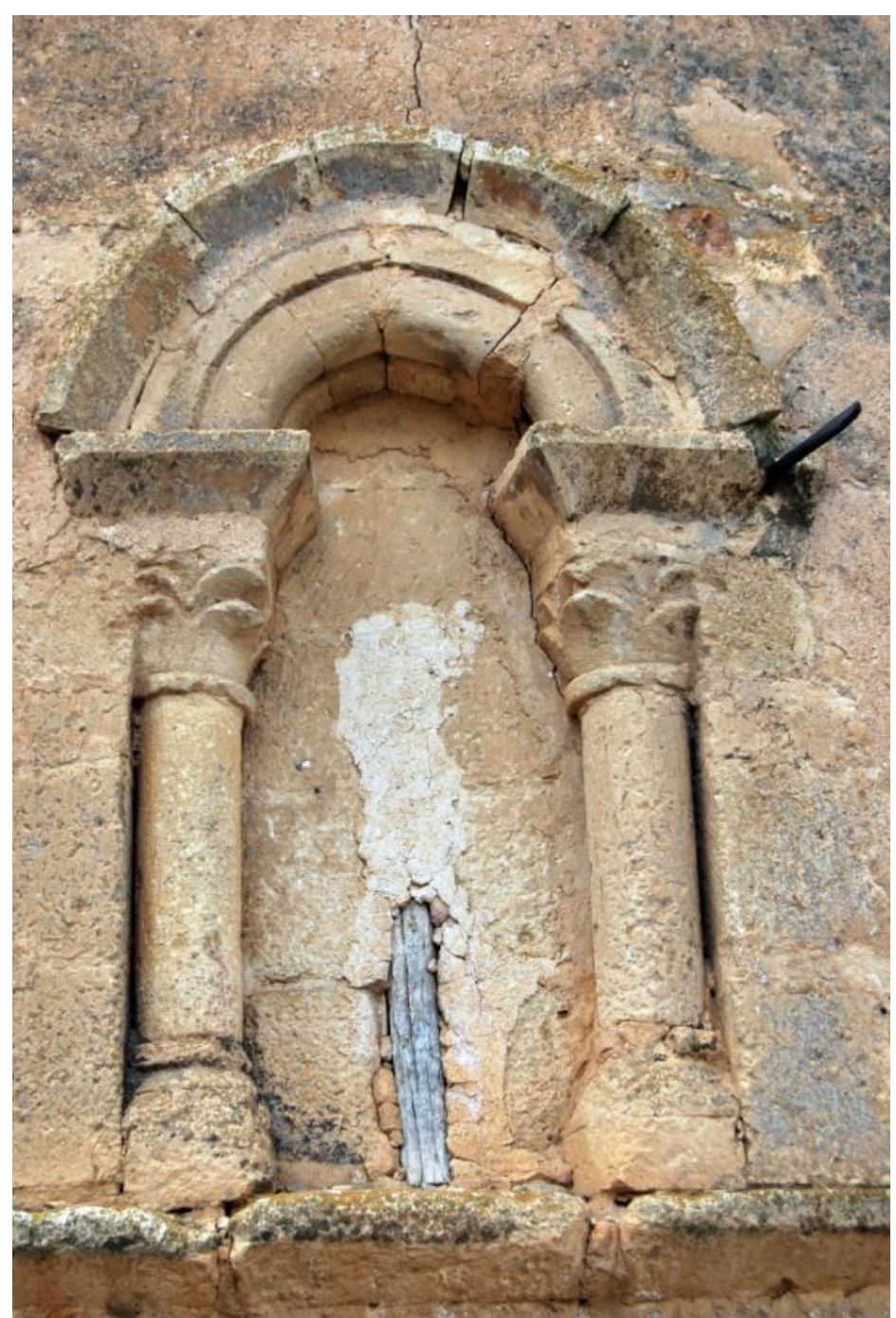

Imagen 1. Detalle de vano.

Asumiendo el origen del ábside y la evolución de la nave como las dos primeras campañas constructivas, una tercera y cuarta correspondería a la adición de la sacristía y el atrio al núcleo primigenio. Bajo la perspectiva de la fenomenología medieval en territorio español, la Iglesia como institución confiere a los lugares repoblados, como Pajarejos, cierta estabilidad y prestigio ante el resto de comunidades (De Hoz Onrubia et al., 2006), por lo que las ampliaciones de este tipo y otras ${ }^{17}$,

15 Si bien algunos investigadores, suelen realizar incisiones en zonas de interés para provocar esta posibilidad de lectura, el trabajo aquí desarrollado, no consideró en ningún momento dicha práctica.

16 No se descarta la posibilidad de la incorporación de otros morteros, especialmente los históricos, para efectos de este tipo de reparaciones. Al respecto, un estudio de caracterización de materiales sería fundamental y apoyaría en gran medida las intervenciones de conservación preventiva.

17 La incorporación de un atrio en la cara sur, y cuyo cometido era sumamente práctico y social: actuaba como lugar de encuentro en el que, al calor del sol, los vecinos se reunían en asambleas o concejos para discutir los asuntos relacionados con la comunidad. Estos concejos alcanzaron un elevado nivel de desarrollo en la época de máximo auge del románico en estas tierras castellanas y respondían a una forma de gobierno mínimamente jerarquizada (De Hoz Onrubia et al., 2006). 
son muy comunes, a más de necesarias ${ }^{18}$. En este sentido, resulta imposible datar la adición de la sacristía. Su relación de posterioridad se manifiesta a través de la inexistente traba con el ábside, así como la disposición de sillares en esquina, en la zona intermedia de la cara Norte, que lo separan del almacén. Pese a la independencia formal, mantiene la misma técnica constructiva de mampostería burda con sillares vistos en esquina. Elemento de interés es la ventana rectangular de gran tamaño enmarcada por sillares regulares de piedra en el paramento Este, donde la relación estratigráfica entre vano y muro asegura su coetaneidad. Atendiendo a la documentación histórica, en el año 1587 se llevarían a cabo obras de cantería y retejado en la sacristía, por lo que su constitución sería previa a finalizar el siglo XVI.

Respecto al pórtico, la transición del ábside hacia el cuerpo Sur se realiza mediante una discontinuidad variable en el muro de mampostería. La singularidad del pórtico reside en el acceso ubicado a Este, a diferencia de la tradicional portada de ingreso consagrada a Sur, hasta conformar una fábrica de sillería perfectamente tallada y perpendicular al ábside. El patente desnivel en el costado Sur respecto a la cota de calle hace inviable aparentemente, una conexión directa desde dicho franco. Por tanto, el acceso en Santo Domingo de Guzmán, atañe a una solución de accesibilidad más que a una cuestión tipológica. ${ }^{19}$ Según la relación estratigráfica, la falta de traba evidencia la relación de posterioridad del atrio porticado, y de la lectura exterior, es apreciable la identificación de diversas fases constructivas coexistentes en el atrio. La portada Este presenta en sus sillares gran diversidad de formatos, irregularidades compositivas, los ya indicados morteros, así como la adaptación de la cubierta a una nueva inclinación, al advertirse un recrecido en diagonal de la línea de cornisa. Del mismo modo se ejecuta el paramento continuo a Sur en todos sus niveles, al detectarse hiladas superpuestas en sentido vertical y la presencia de piedras con formas singulares para adaptarse a una nueva geometría ${ }^{20}$. El margen derecho en consonancia con el desarrollo de la fachada Este, presenta el mayor número de alteraciones al detectarse diversidad de tamaño, resaltos, o la correspondencia de juntas verticales en hiladas diferentes. Así mismo, la no correspondencia de la cornisa con el sistema constructivo de doble hilada de ladrillo de sección semicircular, al ser de sillares de caliza. A diferencia de los pórticos abiertos, la Iglesia de Santo Domingo de Guzmán presenta su atrio totalmente cegado producto de una adición, posiblemente de comienzos del siglo XX. El cegamiento de los vanos se realiza con restos cerámicos sobre adobe, y revestido al exterior con capas superpuestas de mortero. Se ha verificado 1,4 y 5 sub-fases en cada vano respectivamente, -según su disposición en sentido Oeste-Este-, según la superposición progresiva de capas de morteros. En algunos casos el propio revestimiento constituye un motivo decorativo en forma de "ameba" o "riñón"21, que consigue homogeneizar el revestimiento (ver Imagen 2. Detalle de pórtico). Estas irregularidades morfológicas, determinan cierta geometría rectangular coincidente con la carpintería de una ventana cuya exteriorización física es incuestionable en el interior del atrio.

${ }^{18}$ La iglesia en todo asentamiento constituye el principal hito de desarrollo urbanístico. En el caso de la de Santo Domingo de Guzmán la ampliación da nociones claras de la potencialidad de la localidad durante la baja Edad Media.

19 El mismo problema se resuelve en la Iglesia de San Martín -Segovia- que, a causa del fuerte desnivel sobre el que se asienta, el acceso se realiza a Este y Oeste, prolongando el atrio hacia occidente y convirtiéndose en una verdadera vía a nivel urbano. San Pedro de Gaillo (siglo XIII), o la Iglesia de San Miguel de Sotosalbos, son dos ejemplos relevantes, de mayor desarrollo escultórico y ubicación de la puerta de ingreso a Este y Sur.

${ }^{20}$ Es notorio que la estereotomía en L de las piezas en esquina que conforman la albardilla del pórtico, permiten continuar la verticalidad del muro y la adaptación a la inclinación otorgada en todas las piezas. Esta variación de la geometría en los sillares, reiteradamente repetido en el edificio, permite continuar con la construcción del edificio garantizando su estabilidad. Entre las variaciones formales destaca la diversidad de tamaño o resaltos en los sillares o la correspondencia de juntas verticales en dos hiladas diferentes. Pese a la multitud de alteraciones, se indicar cierta coetaneidad en su desarrollo, aun si se considerara que su ejecución es un error constructivo atribuible a la escasa formación de la mano de obra.

21 Este tipo de decoración en fachada, a modo de esgrafiado, es muy peculiar tanto en la zona rural segoviana como en la capital. 


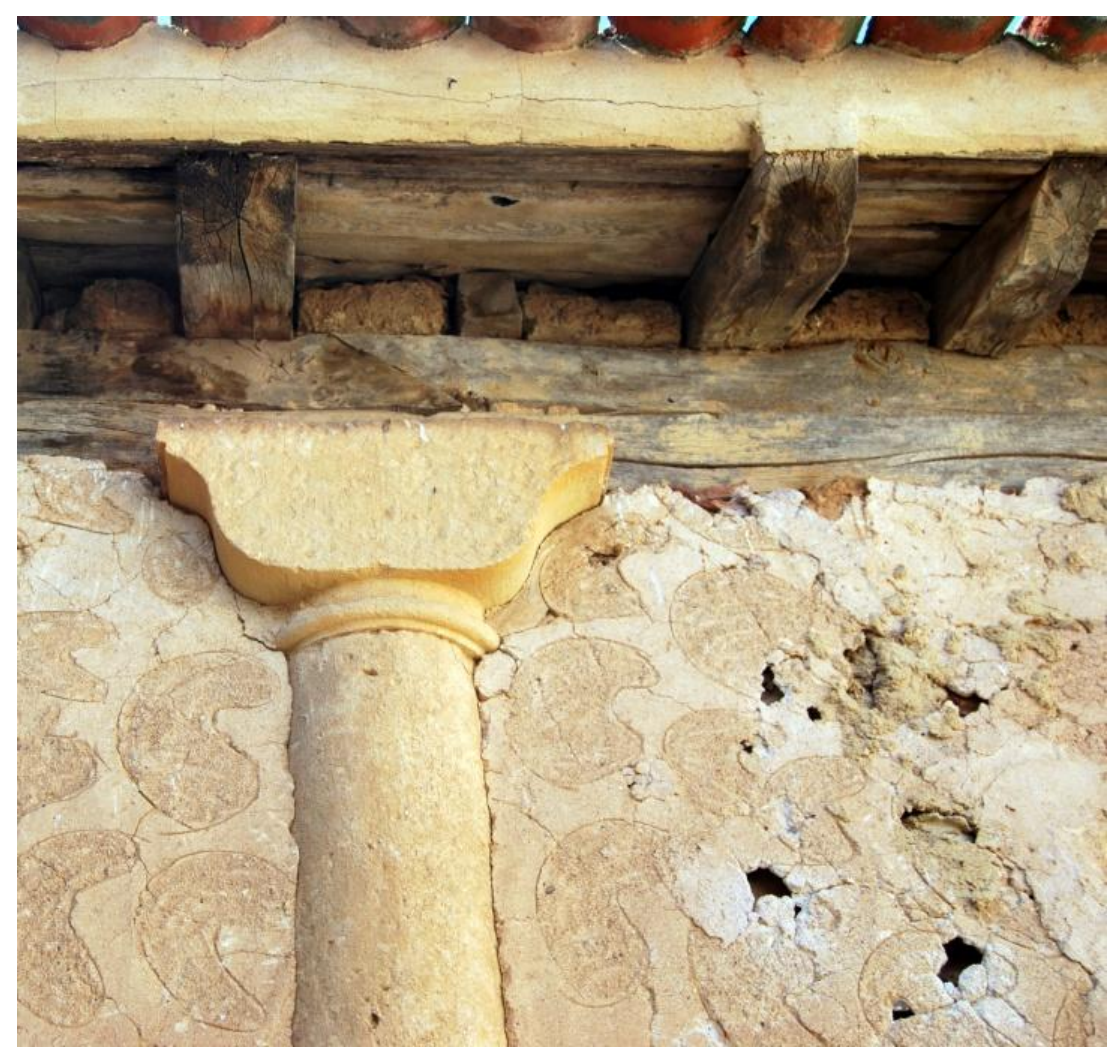

Imagen 2. Detalle de pórtico.

Ante este palimpsesto, es evidente la dificultad de fechar con precisión el cuerpo Sur, ya sea en su relación al conjunto o de manera independiente. Cabe indicar que, pese a la multitud de alteraciones, existe cierta coetaneidad en su constitución, por lo que su ejecución podría deberse a varios motivos, incluyendo la escasa formación de los operarios. Según la documentación histórica, se tiene constancia de la remodelación del pórtico entre 1617-1626. Esta etapa correspondería a la sexta fase constructiva y, aunque descrita desde diversas perspectivas que prestan a confusión, deja ver la importancia de su incorporación y transformación constante, en estilo y tipo de piedra (Moreno Alcalde, 1988), clasifica este tipo de alteraciones y empleo de piedra caliza al sistema constructivo imperante por la Catedral de Segovia (1525-1607) 22 .

Contemporáneo a la sacristía y el atrio, la erección de la espadaña define la quinta campaña, tanto en base a la lectura estratigráfica como a la documentación histórica. Su construcción data de 1609, sin muestras evidentes de preexistencias con facciones similares. Previo a la culminación del cuerpo occidental, la nave pudo alcanzar su máximo desarrollo longitudinal en fechas anteriores, sin ser posible una vez más determinar la exactitud temporal y espacial su expansión occidental al presentar un revestimiento continuo en el interior, que limita toda posibilidad de lectura sistemática. La espadaña se erige entonces, como un volumen constituido por tres cuerpos diversos. Frente al muro burdo de mampostería y sillares en esquina en la parte baja, se alza el cuerpo superior con factura de fábrica de sillería, separado del anterior por una marcada línea de imposta. La heterogeneidad de sillares así como la falta de horizontalidad entre hiladas, la reiterada y característica existencia de piezas en forma de L, o la distinción entre el frontón triangular del resto, mediante un cornisa corrida en el perímetro, hace factible la identificación de las múltiples fases constructivas, que pudieran incluso ser coetáneas atendiendo a sus relaciones estratigráficas. A su vez, la presencia de dos arcos

${ }^{22}$ El primer momento coincide con el siglo XV y los comienzos del siglo XVI, hasta 1525. Está dominado por la tradición previa y el empleo de un determinado tipo de elementos constructivos. El segundo momento se da a partir de 1607, desde cuando parece decisiva la influencia de la catedral nueva de Segovia, con una búsqueda de monumentalidad y la utilización de motivos complejos. 
de medio punto en el cuerpo principal, y una tercera abertura en el frontón triangular, sugieren cierta homogeneidad de ejecución, por lo que respalda la hipótesis de una construcción acometida en un mismo periodo. Para generar un acceso interno a la espadaña -por fines litúrgicos principalmente-, se crea un espacio de reducidas dimensiones denominado garita, que define una séptima campaña constructiva fechada en 1623, posterior a la ejecución del pórtico, pero en fase previa a la reforma de las portadas -fase 8-. La documentación histórica revela la construcción en 1643 de la armadura de cubierta, al mismo tiempo que se realizan obras de intervención en el cuerpo de la iglesia, sacristía y tabernáculo, configurando una novena campaña, únicamente en base a lo expuesto.

La conformación de la imagen actual de la iglesia alcanza su punto álgido al añadir a Norte el cuerpo de almacenes. Ésta situación se ratifica con la existencia de tres hileras verticales de sillares de piedra de buena factura, dos de las cuales marcan la evidente distinción con los cuerpos contiguos. La primera hilada vertical divide la espadaña con los almacenes en la cara Oeste; sin embargo, pese al empleo del mismo sistema constructivo, es clara su independencia, al no distinguirse ningún elemento de traba coherente, sumado a la diferencia de tamaño entre sillares. La segunda hilada actúa como muro divisorio entre la sacristía y el nuevo cuerpo, presentando las mismas características morfológicas. Al igual que en la cabecera, el cuerpo del almacén se ejecuta en base a un zócalo de sillares de piedra de corto desarrollo sobre el que se asienta un muro de mampostería, prácticamente inapreciable a causa de las sucesivas capas de mortero. Destaca el empleo de cargaderos de piedra sobre jambas de sillería de perfecta labra, definiendo los vanos de puertas. Se usan fragmentos de balaustrada para la apertura de ventanas, probablemente reutilizadas (ver Imagen 3. Detalle de vano a Norte). Sin que se haya podido determinar su procedencia, se cree podrían pertenecer al templo primitivo o a algún otro edificio del sector. La totalidad de la fachada Norte se ve envuelta por abundantes capas de mortero, cuya aplicación concierne a fases complementarias. Destaca un escaso fragmento que en aspecto replica sillares de piedra, y que supone que en algún momento la imagen del edificio estaba determinada por este.

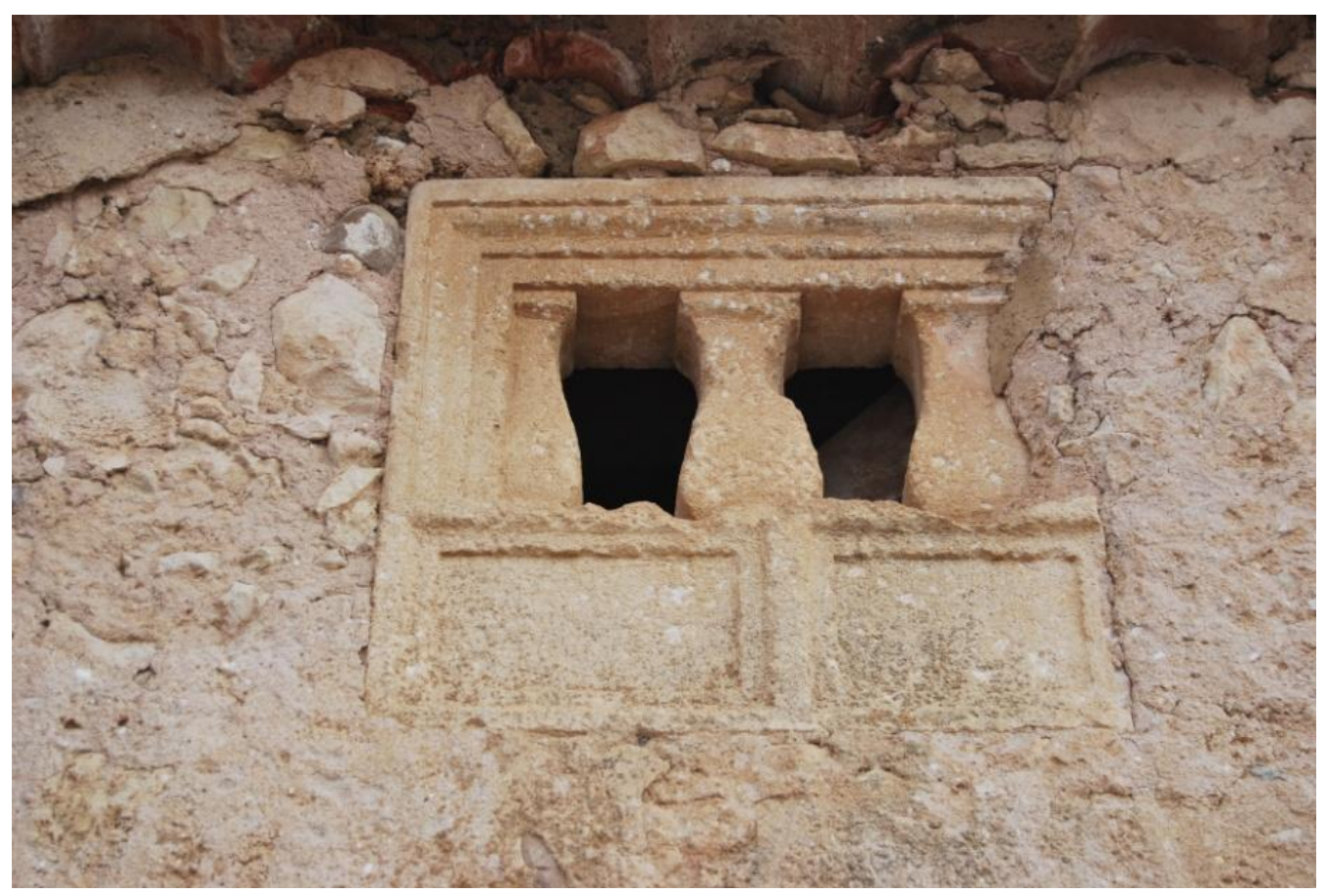

Imagen 3. Detalle de vano a Norte.

Al presentarse cubierta y cornisa como elementos continuos, interrumpidos únicamente por la espadaña y la variación formal del pórtico Sur -fase 11-, y en base a las relaciones estratigráficas de posterioridad, se identifica la duodécima fase. La pulcra homogeneidad en tratamiento y materiales, argumenta su correspondencia a una misma etapa constructiva, más reciente que el resto del 
conjunto $^{23}$. La última campaña -fase 13-, albergaría todos aquellos elementos de carácter secundario del edificio. Se incluyen carpinterías expresivamente modernas, rejerías, elementos estructurales de acceso a la espadaña e incluso revestimientos de mortero, que, tanto por sus características formales como por su ejecución, constituyen elementos que no alteran en exceso la imagen formal, ni determinan actuaciones fundamentales.

Finalmente, sin llegar a acometer un estudio pormenorizado del interior, se cree que el edificio también puede albergar un conjunto valioso en cuanto a estratigrafía de subsuelo, como consecuencia de los procesos de transformación descritos previamente, en especial en la fase de construcción de la portada Sur y espadaña. Aunque de momento no se ha considerado el configurar una propuesta desde este campo, que asista al resolver la totalidad de planteamientos iniciales sobre el inmueble, el presente estudio, se constituye como el más completo análisis sobre la Iglesia de Santo Domingo de Pajarejos, ilustrado a través de la Imagen 4: Planta evolutiva del conjunto arquitectónico (ver Imagen 5: Alzados estratigráficos, e Imagen 6: Síntesis de the Harris Matrix).

\section{DISCUSIÓN}

A la vista de los resultados y siguiendo el hilo argumental de la discusión sobre la dimensión teóricopráctica del análisis estratigráfico, su aplicación ha permitido alcanzar un conocimiento veraz con tintes históricos sobre la Iglesia de Santo Domingo de Guzmán en Pajarejos, elevando a la presente, como el mayor estudio acometido hasta el momento. La visión holística de la dinámica constructiva del edificio alcanzada con el análisis estratigráfico es un notable aporte frente a las escasas fuentes documentales. Este esfuerzo ofrece una aproximación a su configuración histórica, proceso que, por otros medios, sería prácticamente imposible, al tiempo que evita contemplar la obra como un producto cerrado y estático sino como un ente vivo en transformación (Latorre, 2007: 47, citando a Lowenthal (1985: 570-573)), producto de un devenir constante, marcado por factores diversos. Este tipo de análisis además, evita el llamado punto muerto historiográfico (Caballero Zoreda, 2009: 115; Azkarate, 2010), común ante el subjetivismo del investigador que categoriza basándose en criterios estilísticos. Sin menospreciar los contenidos de la Enciclopedia del Románico (VV.AA, 2007: 10591062), la aplicación del análisis estratigráfico comprende el objeto arquitectónico como fruto de múltiples lecturas, destacando su horizonte espacial, temporal y social (Caballero Zoreda, 1997). Sin embargo, su aplicación no se ha de considerar la panacea para la documentación del patrimonio arquitectónico, sino una herramienta más, cuya configuración logra un conocimiento satisfactorio y pleno (Mileto \& Vega, 2003: 162).

De cara a la dimensión teórica, la discusión se centra en la veracidad del análisis como proceso documental. En el ámbito técnico y operativo ${ }^{24}$, la implementación, difusión y conocimiento de este tipo de estudios, dentro de los procedimientos de la cadena de valor del patrimonio, esto es identificación, documentación y registro, valoración y significación, intervención y conservación, difusión y socialización, impacto y reflexión, patrimonio (Azkarate et al., 2009: 606), aunque aún limitado, es fundamental para contextualizar el ente de estudio, (Azkarate, 2010: 54) así como su complementariedad a los estudios tradicionales subyacentes. Si bien, su ejecución sobre la base de la presente experiencia, la impericia que pudiese significar, así como sobre otras referencias semejantes (Barluenga et al., 2014; Mileto \& Vegas, 2003; Blanco Rotea, 2003 \& 2005), sus potencialidades son altamente objetivas, aún más para el conocimiento de edificios históricos en los cuales se carece de documentación previa. La arquitectura monumental, de mediana y pequeña escala, como el caso de la

23 Según conservaciones mantenidas con miembros de la parroquia y algunos vecinos, recientemente se han acometido obras de reparación en el tejado cuya ejecución no concierne a una etapa tan puntual como la generación de una cornisa unitaria y la disposición de la totalidad de las tejas al estilo segoviano, es decir mediante la disposición únicamente de tejas a canal, sin la típica cobija propia del resto de España.

${ }^{24}$ Considerándose como tal incluso el ámbito procedimental a nivel del ejercicio profesional en el ámbito público cuanto privado de la intervención en edificios históricos, sobre todo en centros históricos, cuya tendencia es una constante en crecimiento a nivel mundial. 


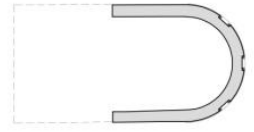

$01_{\text {fase }}$

ábside. S.XII-XIII

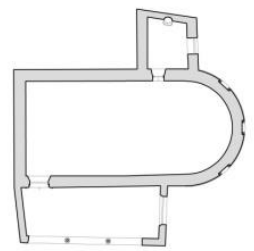

04 fase

pórtico. s.XIV?

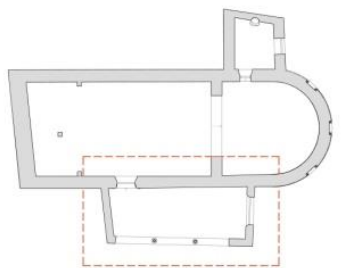

06 fase

reforma de la portada.1617-1626

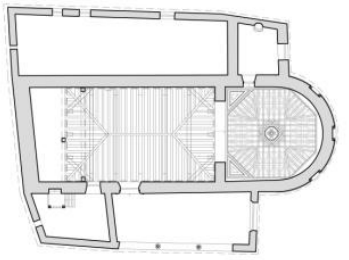

09 armadura interior.1643

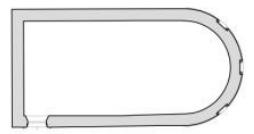

02 fase

nave central. s.XIII-XIV

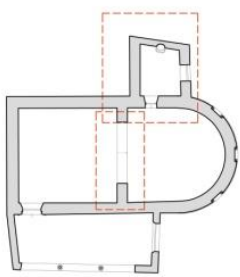

04. $1_{\text {fase }}$ intervenciones puntuales

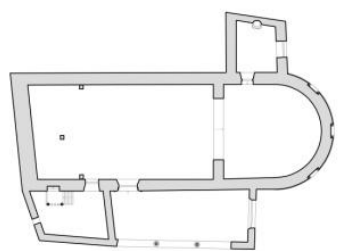

07 fase

garita.1623

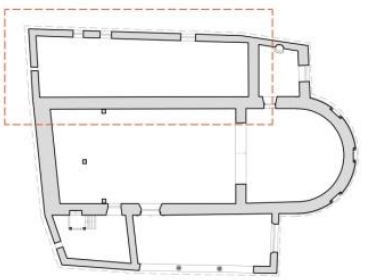

10 iase

almacén.s. XVIII?

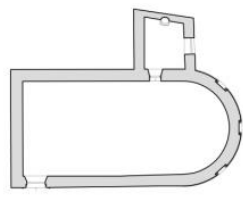

03 fase

sacristia. s.XIV-XV

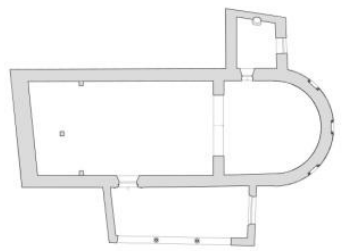

05 fase

espadaña. 1609

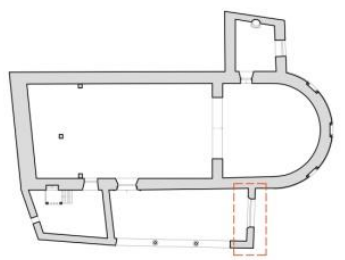

08 fase

reparación de portadas. 1626

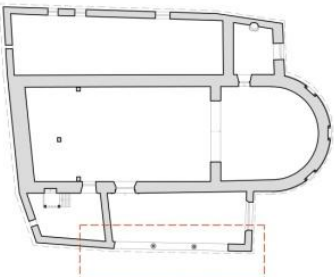

$11_{\text {fase }}$

viga del pórtico

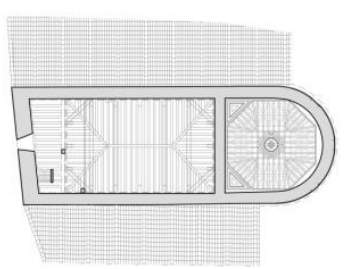

12 fase

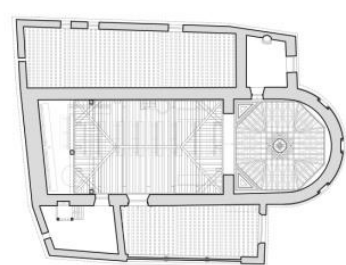

13ase intervenciones posteriores

Imagen 4. Planta evolutiva del conjunto arquitectónico.

vivienda rural vernácula en tierra localizada en la Rioja (Rolón \& Rotondaro, 2010), son objetos de estudio probados y con resultados de interés, más aun cuando llevado a niveles BIM y HBIM, el método ratifica su potencialidad y nivel de operatividad en la gestión de información (Brumana et al., 2013). Su aplicación como parte de la labor investigadora, debe insertarse planificada y 
oportunamente dentro de los procesos de actuación previa, ya que se efectúan una vez iniciada la obra de intervención (Lecanda, 2003), y limita a tareas de excavación puntual, comúnmente a nivel de subsuelo, desconociendo la necesidad del estudio del conjunto arquitectónico.
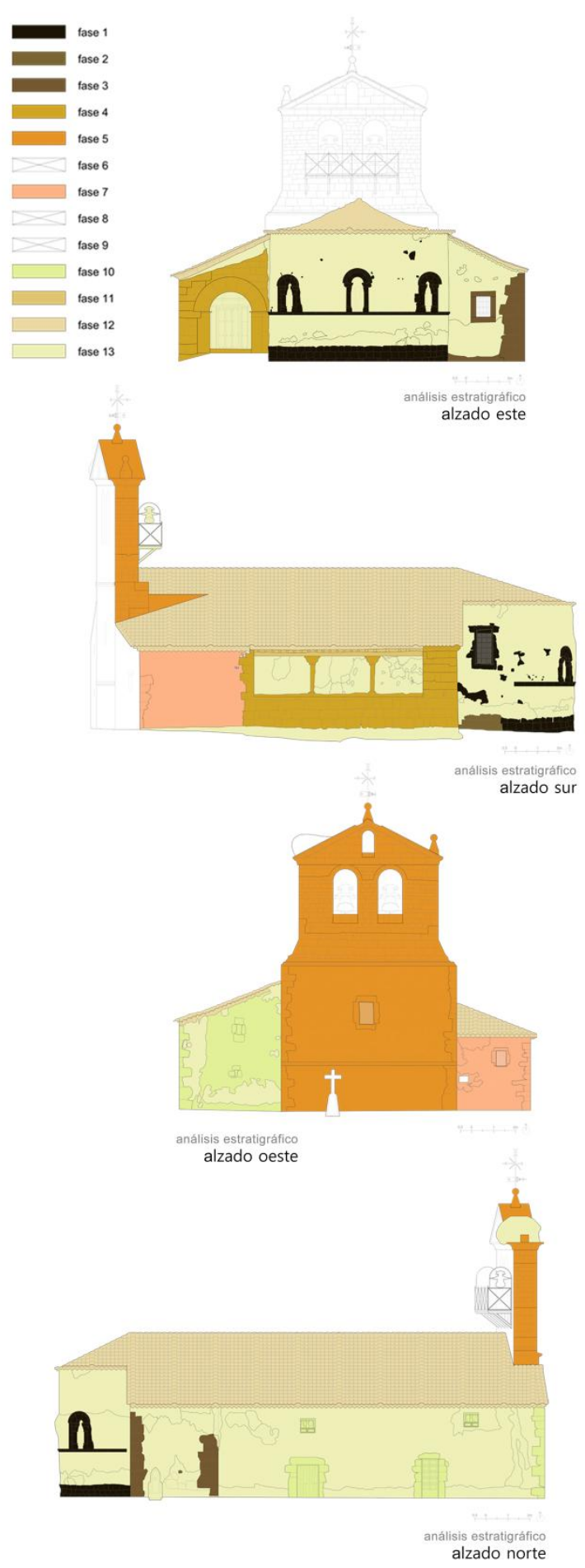

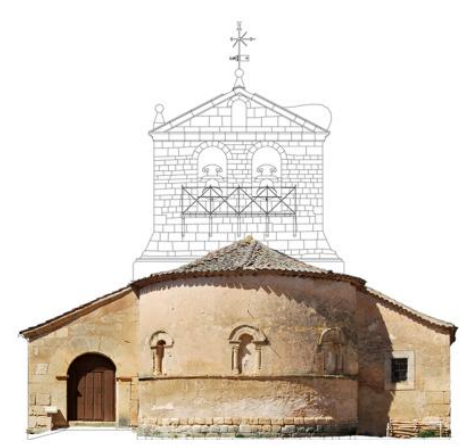

alzado este
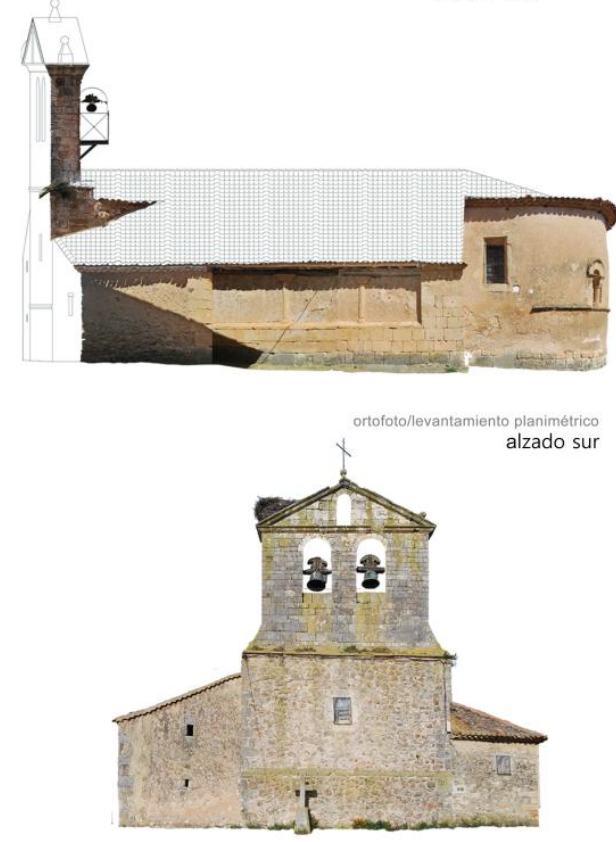

alzado oeste

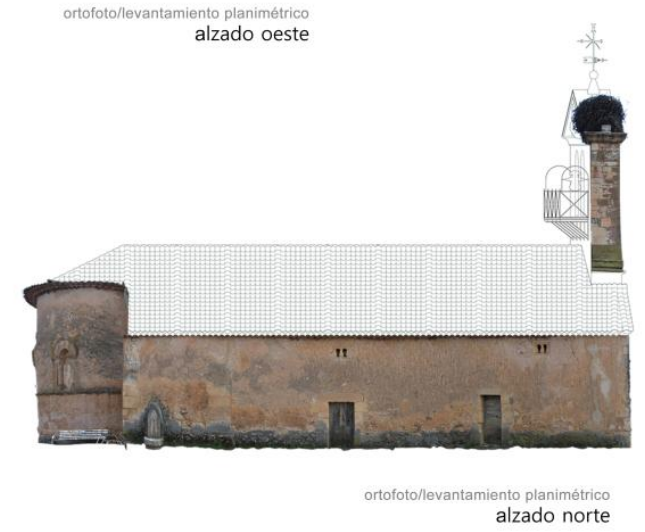

Imagen 5. Alzados estratigráficos. 


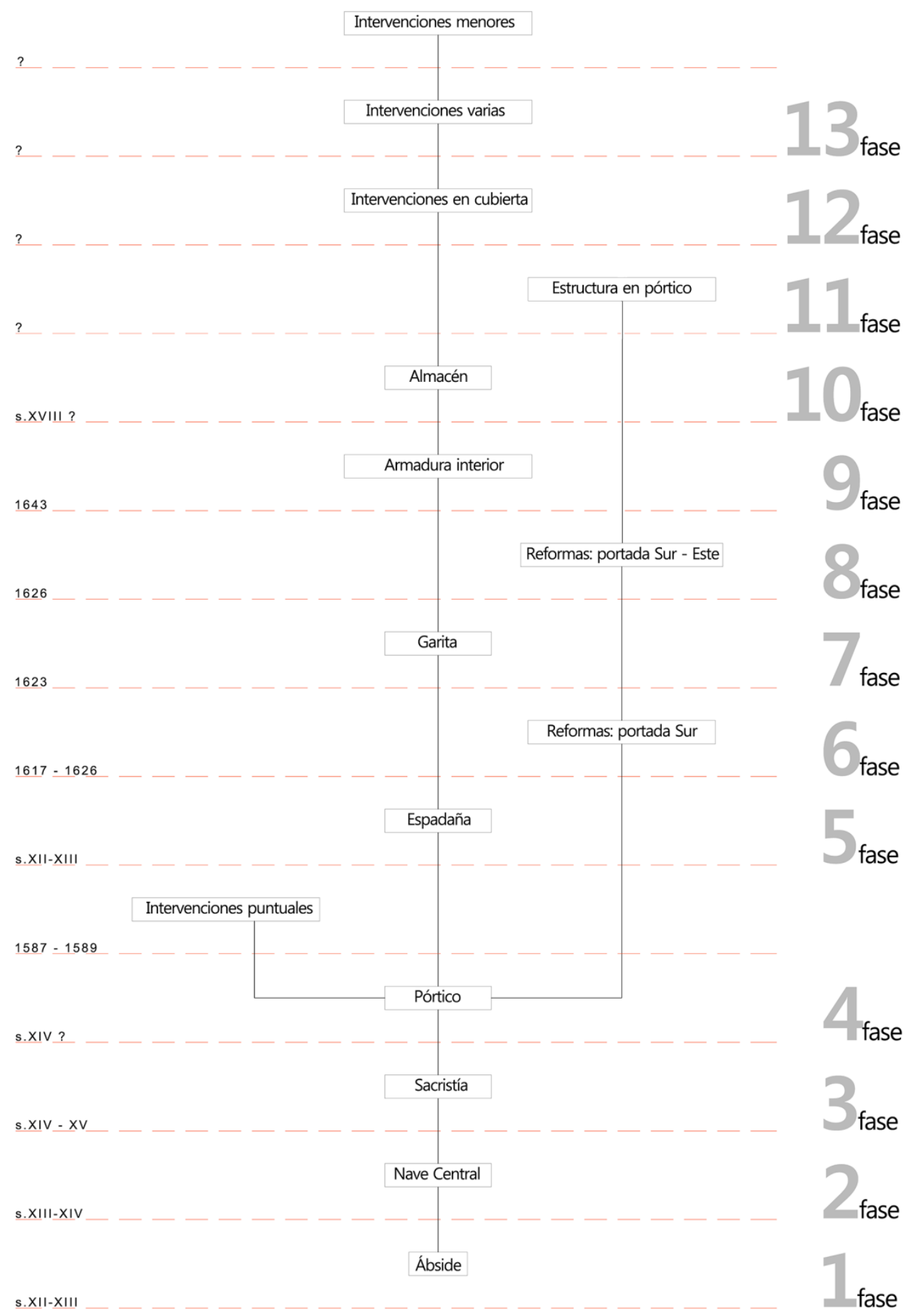

Imagen 6. Síntesis de the Harris Matrix.

Desde otra perspectiva, el método no deja de ser, por sí sólo, un procedimiento sin nivel operativo (Mileto \& Vegas, 2004: 156), con la peculiaridad de tener como fuente primaria al edificio, al que decodifica y ordenar diacrónicamente desde su complejidad constructiva intrínseca (Azkarate et al., 2009: 602) para constituir un mejor y mayor entendimiento de su realidad, las técnicas de construcción y las características de los materiales utilizados, a diferencia de recurrir a documentos y legajos históricos. La caracterización de Santo Domingo de Guzmán, y de otros edificios, 
principalmente aquellos "no singulares", supone un valor añadido dado por la valoración de la población sobre el patrimonio local, y con ello el fomento de la recuperación de la identidad frente a mecanismos de globalización que paulatinamente se introducen. Su puesta en práctica favorece la conservación y valor fomentando apropiación e involucramiento, donde la implicación activa de jóvenes restauradores anima a la participación ciudadana. Consecuentemente, permite precisar desde la perspectiva social la configuración histórica, evolución volumétrica y constructiva, coexistencia material, soluciones entre sistemas constructivos, etc., que constituyen información de primera mano para la determinación de posturas de intervención ${ }^{25}$, e incluso niveles de protección, atendiendo a valores de autenticidad e integridad reconocidos en la Carta de Nara, por ejemplo y otros tradicionalmente debatidos como el valor histórico, de antigüedad y documental (Latorre \& Caballero, 1995).

\section{CONCLUSIONES}

El presente estudio, a nuestro criterio exhaustivo, del templo románico de Santo Domingo de Guzmán en Pajarejos (Segovia) supone la única aproximación a la identificación constructiva-evolutiva y crítica del conjunto arquitectónico, en sus trece fases de desarrollo diacrónico. El edificio, en su configuración actual, es fruto de una serie de intervenciones, tanto de ampliación y añadido de nuevos cuerpos, como de transformación de los paramentos preexistentes. Gracias a la aplicación del análisis estratigráfico, ha sido posible dicha caracterización, así como entender el bien edificado como documento histórico y objeto arquitectónico ${ }^{26}$. Frente a esta visión, se ha de sumar nuevas investigación basados en campos de reciente interés, desenmascarando algunos interrogantes propios de investigaciones acometidas hasta el momento.

Atendiendo al conocimiento técnico, en su aproximación más científica (Caballero Zoreda, 1995: 44) el análisis del edificio de Santo Domingo de Pajarejos, representa como fuente primaria, además de ilimitada (Mileto \& Vegas, 2004: 156), y en correspondencia con los fines de la arqueología de la arquitectura, un proceso de enriquecimiento patrimonial, donde tiempo y espacio aparecen estrechamente fundidos en el ritmo que lo configura, y con ello, la determinación de campañas constructivas que lo definen. Como resultado, se puede afirmar categóricamente que la iglesia constituye un ejemplo más del románico segoviano, cuya transformación a partir de su célula primigenia y a la lógica constructiva de las intervenciones que sobre ella se realizaron desde los ámbitos litúrgico, sociológico y político ${ }^{27}$ le han convertido en un ente singular.

La configuración de este nivel de conocimiento debe apoyar la identificación de acciones concretas apostando a la conservación material respetuosa del edificio (Mileto \& Vegas, 2004: 162;

${ }^{25}$ Los partidarios de la intervención, entienden el edificio como un problema de construcción, de mecánica, de estática, de espacio, de luz, de tipología, de estilo, de contenedor de actividades humanas, etc., en definitiva, como un problema de arquitectura. Los partidarios de la conservación valoran el edificio como un documento histórico y exigen la "autenticidad" del material que lo conforma, pues saben que cualquier intervención puede hacer desaparecer algún elemento primordial para la comprensión de la historia del mismo (Latorre \& Caballero, 1995).

${ }^{26}$ Por lo que respecta al monumento como documento, el arquitecto debe promover el análisis previo mediante un estudio arqueológico. Sin embargo éste no tendrá necesariamente una vinculación directa con el proyecto, salvo en el caso en el que se trata de un edificio en ruina y desuso.

Considerando el monumento como objeto arquitectónico, debe asumirse la necesidad de actuar de formar que el arquitecto aporte lo mejor que tenga al edificio como una fase más de las que éste manifiesta, de igual modo que en su momento cada arquitecto incorporó según su época los gustos estilísticos en boga (Tabales Rodríguez, 2002).

27 Brandi reconoce, que las condiciones sufridas por una obra de arte no son más que nuevos testimonios del quehacer humano, y por tanto de la historia, considerando evidente entonces que lo añadido puede completar o ampliar, funciones diferentes de las iniciales (Brandi, 1988: 40-41). Igualmente Latorre \& Caballero (1995: 5-18) reconocen que forma, construcción, función y entorno determinan simultáneamente tanto la génesis de su arquitectura como la de las transformaciones a las que se verá sometido. 
Mileto \& Vegas, 2009: 189). Exige responsabilidad y compromiso profesional (Mileto \& Vegas, 2003: 162), tal que, consecuentemente, garantice la conservación de la Iglesia de Santo Domingo de Guzmán, como una edificación dentro de las red de templos románicos segovianos y referente del mismo. Los resultados alcanzados, aunque fruto de requerimientos académicos, dan idea del interés y conveniencia de esta clase de estudios donde profesionales de distintas áreas son capaces de trabajar conjuntamente para generar un conocimiento integral y holístico. La asimilación del método y su puesta en práctica, demanda la implicación activa en el proceso de documentación de arquitectos y otros técnicos, constituyendo verdaderos equipos multidisciplinares.

Finalmente, y a criterio propio, se recomienda el ensayo del método en los procesos de caracterización del patrimonio, al constituir una herramienta versátil y exponencialmente objetiva. Bases de datos avaladas como la llamada ABACO, de propiedad del Instituto Nacional de Patrimonio Cultural, -INPC- del Ecuador podrían bajo la aplicación de procesos críticos y técnicos de selección, identificar muestras de interés para su aplicación, así como, la validación del método en el contexto territorial.

\section{AGRADECIMIENTOS}

Realizar un estudio de investigación es tarea complicada, al menos si la herramienta aprendida durante la formación académica no ha sido la palabra. En este sentido, esperamos haber logrado el balance justo entre rigor y claridad. Si este balance se obtuvo, será en buena medida gracias a un número de personas que han influido en el proceso. En primer lugar a Fernando Vela Cossío y Alejandro García Hermida, por la instrucción y guía en el campo de la lectura estratigráfica, el entusiasmo necesario para ejecutar este trabajo, y la motivación para futuras empresas. A Gonzalo López Muñiz por su asistencia en tanto a la documentación histórica, y a Elina Rodríguez Millán y Oscar Senabre Gómez, por su participación en el levantamiento y procesamiento de la información base.

\section{BIBLIOGRAFÍA}

Azkarate, A., D. Barreiro, F. Criado, I. García Camino, S. Gutiérrez Lloret, J.A. Quirós, V. Salvatierra, 2009. La Arqueología Hoy. Actas del Congreso Medio Siglo de Arqueología en el Cantábrico Oriental y su Entorno, Vitoria-Gasteiz, España, 599-615.

Azkarate, A., 2010. El análisis estratigráfico en la restauración del patrimonio construido. En E. de Vega, C. Martín (dir.). Actas del congreso Arqueología aplicada al estudio e interpretación de edificios históricos. Últimas tendencias metodológicas. Ministerio de Cultura, Subdirección General Técnica de Publicaciones, Información y Documentación, Madrid, España, 51-63.

Barluenga, G., F. Estirado, R. Undurraga, J.F. Conde, F. Agua, M.A. Villegas, M. García-Heras, 2014. Brick masonry identification in a complex historic building, the Main College of the University of Alcalá. Constr. Build. Mater., 54, 39-46.

Blanco Rotea, R., 2003. Arquitectura como construcción estratificada. Arqueología de la Arquitectura, 2, 55-62.

Blanco Rotea, R., 2005. Análisis de la Iglesia Parroquial de Santa María de Castro (Cervantes, Lugo). Cuadernos de Estudios Gallegos, Tomo L1J, Fascículo 118, Santiago, España, 9-38.

Brandi, C., 1988. Teoría de la restauración. Editorial Alianza, Madrid, España, 156 pp.

Brogiolo, G.P., 1988. Archelogia dell'edilizia storica. Museu Cívico Archeologico di Como, New Press, Como.

Brogiolo, G.P., 1988. Campionatura e obiettivi nell'analisi stratigrafica degli elevati. En: Francovich, R., R. Parenti, Archeologia e restauro dei monumento, Universidad de Siena, 335346. 
Brogiolo, G. 1995. Arqueología estratigráfica y restauración. Consejo Superior de Investigaciones Científicas, Madrid, España. Inf. Constr., 46(435), 31-36.

Brumana, R., D. Oreni, A. Raimondi, A. Georgopoulos, A. Bregianni, 2013. From survey to HBIM for documentation dissemination and management of built heritage. The case study of St. María in Scaria d'Intelv. Urban Atlas and Built Environment Surveying, SDI-BIMGIS, IEEE, 497-504.

Caballero Zoreda, L., 1995.Método para el análisis estratigráfico en construcciones históricas o Lectura de paramentos. Consejo Superior de Investigaciones Científicas, Madrid, España. Inf. Constr., 46(435), 37-46.

Caballero Zoreda, L., 1997. Arqueología y arquitectura. Análisis arqueológico e intervención en edificios históricos. Curso: As actuacións no patrimonio construido: un diálogo interdisciplinar. Fontenla San Juan, Concha (Coordinador), Xunta de Galicia, Consellería de Cultura, Dirección Xeral do Patrimonio Histórico e Documental, Galicia, España, 457-469.

Caballero Zoreda, L., 2004. Experiencia metodológica en arqueología de la arquitectura de un grupo de investigación. En E. de Vega, C. Martín (dir.). Actas del congreso Arqueología aplicada al estudio e interpretación de edificios históricos. Últimas tendencias metodológicas. Ministerio de Cultura, Subdirección General Técnica de Publicaciones, Información y Documentación, Madrid, España, 103-119.

Caballero Zoreda, L., 2009. A propósito del centenario del 711. Apuntes sobre método de la arqueología de la arquitectura. Anales de Historia del Arte, 22(II), 101-130.

De Hoz Onrubia, J., L. Maldonado Ramos, F. Vela Cossio (coor.), 2006. El lenguaje de la arquitectura románica. Mairea Libros (Ed.), Escuela Técnica Superior de Arquitectura de Madrid, Madrid, España.

Doglioni, F., 1997. Stratigrafia e restauro. Editorial Lint, Trieste, 312 pp.

Doglioni, F., 1988: La ricerca nelle struttura edilizia tra Archeologia stratigrafica e restauro architettonico. En: Francovich, R., R. Parenti, 1988. Archeologia e restauro dei monumento. I ciclo di lezioni sulla ricerca aplicata in archeologia. Certosa di Pontignano (Siena), Firenze, 1987. 223-247.

Fiorini, A., 2011. Dal castrum altomedievale al restauro settecentesco: storia e archeologia del castello di Sorrivoli (Roncofreddo-FC). Arqueología de la Arquitectura, 8, 219-238.

González-Moro, P.L., L. Caballero Zoreda, 1995. La importancia del análisis estratigráfico de las construcciones históricas en el debate sobre la restauración monumental. Inf. Constr., 46(435), $5-18$.

Harris, E., 1991. Principios de Estratigrafía Arqueológica. Editorial Crítica, Barcelona, España.

Latorre, P., L. Caballero, 1995. La importancia del análisis estratigráfico en las construcciones históricas en el debate sobre la restauración monumental. Consejo Superior de Investigaciones Científicas, Madrid, España. Inf. Constr., 46(435), 5-18.

Latorre, P., 2010. La conservación del tiempo en la restauración: el proyecto estratigráfico. En E. de Vega, C. Martín (dir.). Actas del congreso Arqueología aplicada al estudio e interpretación de edificios históricos. Últimas tendencias metodológicas. Ministerio de Cultura, Subdirección General Técnica de Publicaciones, Información y Documentación, Madrid, España, 25-49.

Lecanda, J.A., 2003. Análisis estratigráfico del cuerpo de torres de la Catedral Vieja de Salamanca. Arqueología de la Arquitectura, 2, 159-165.

Lowenthal, D., 1985. El pasado es un país extraño. Madrid, España, 570-573.

Manacorda, D., 1989. Archeologia e informatica: Il contributo dei calcolatori alla conoscenza scientifica deimonumenti. Note di informatica, 21, 13-24.

Mileto, C., F. Vegas, 2003. El análisis estratigráfico constructivo como estudio previo al proyecto de restauración arquitectónica: metodología y aplicación. Arqueología de la Arquitectura, 2, 189196.

Mileto, C., F. Vegas, 2004. El análisis estratigráfico constructivo y el proyecto de restauración arquitectónica. Arqueología de la Arquitectura, 3, 155-162. 
Mileto, C., F. Vegas, 2010. El análisis estratigráfico: una herramienta de conocimiento y conservación de la arquitectura. En E. de Vega, C. Martín (dir.). Actas del congreso Arqueología aplicada al estudio e interpretación de edificios históricos. Últimas tendencias metodológicas. Ministerio de Cultura, Subdirección General Técnica de Publicaciones, Información y Documentación, Madrid, España, 145-158.

Moreno Alcalde, M., 1988. La tierra de Segovia: Arquitectura religiosa y escultura monumental en el periodo gótico. Tesis Doctoral. Universidad Complutense de Madrid, Madrid, España.

Parenti, R., 1988. Le tecniche di documentazione per una lettura stratigrafica dell'elevato. En: Francovich, R., R. Parenti, Archeologia e restauro dei monumento, Universidad de Siena, Siena, 249-279.

Rolón, G., R. Rotondaro, 2010. Dal castrum altomedievale al restauro settecentesco: storia e archeologia del castello di Sorrivoli (Roncofreddo-FC). Arqueología de la Arquitectura, 7, $213-$ 222.

Sánchez Zufiaurre, L., 2004. Un método de prospección en arqueología de la arquitectura. La arquitectura medieval invisible. Arqueología de la Arquitectura, 3, 185-197.

Tabales Rodríguez, M.A., 2002. Sistemas de análisis arqueológico de edificios históricos, Tesis Doctoral. Universidad de Sevilla, Secretariado de Publicaciones, Sevilla, España, 95 pp.

Vargas Lorenzo, C., 2013. Reflexiones sobre cronotipologías en arqueología de la arquitectura. Métodos y sistemas de análisis, Arqueología de la Arquitectura, 10, 1-26.

VV.AA, 2007. Enciclopedia del Románico en Castilla y León, Segovia, Vol. II, Fundación Santa María la Real, Aguilar de Campoo, España, 1059-1062. 